\title{
Optimization of the Ground Observation
}

\section{Jan Mazal ${ }^{1 *}$, Agostino G. Bruzzone ${ }^{2}$, Libor Kutěj ${ }^{1}$, Radomir Scurek ${ }^{3}$ and Daniel Zlatník ${ }^{4}$}

${ }^{1}$ University of Defence, Brno, Czech Republic

${ }^{2}$ Simulation Team, University of Genoa, Italy

${ }^{3}$ VŠB-TU Ostrava, Czech Republic

${ }^{4}$ Multinational Logistics Coordination Centre (MLCC), Prague, Czech Republic

*Corresponding author. Email address: jan.mazal@unob.cz

\begin{abstract}
Increasing dynamics and complexity of the operational environment will have a serious impact on the human performance in various decision-making tasks, which were intuitively solved in the past with vast application of the human experience and estimation. The paper deals with the problem of the area ground observation optimization, which is very common in the wide set of observation tasks and its automation by the UGV's or other assets. The problem is defined as a minimization of the observation point count within selected area to cover (by observation) the maximum of the target area. The problem solution complexity depends on variety of other assumptions, especially if we consider the observation point in other "tactical" ways, particularly the observation point carry other attributes which plays the role in the chaining of these points within a reconnaissance path.
\end{abstract}

Keywords: Observation, Optimization, UGV, ISR, Reconnaissance, Visibility

\section{Introduction}

Contemporary highly dynamic operational environment brings many new challenges, which were not apparent before. One of the today's significant trends in military is continuous pursue for the effectiveness and its improvement in context of lack of qualified personnel. Increasing dynamics and complexity of the operational environment will have a serious impact on the human performance in various decision-making tasks, which were intuitively solved in the past with vast application of the human experience and estimation.

The paper deals with the problem of the area ground observation optimization, which is very common in the wide set of observation tasks and its automation by the UGV's or other assets. The problem is defined as a minimization of the observation point count within selected area to cover (by observation) the maximum of the target area. The problem solution complexity depends on variety of other assumptions, especially if we consider the observation point in other "tactical" ways, particularly the observation point carry other attributes which plays the role in the chaining of these points within a reconnaissance path. This gives the motivation for development of the solution of discussed problem, which could be further optimized and automated, saving the human effort and increase effectiveness in the mission management.

\section{State of the art}

Even thought a lot of publications was written about visibility algorithms and analyses, there is not many publications dedicated to the area of ground visibility, the approaches are mainly based on PSO (Particle

(C) 2020 The Authors. This article is an open access article distributed under the terms and conditions of the Creative Commons Attribution (CC BY-NC-ND) license (https://creativecommons.org/licenses/by-nc-nd/4.0/). 
Swarm Optimization) or SA (Simulated Annealing). Mentioned topical area still hide a vast potential for improvement is still an actual operational issue in context of automation and future operational environment, the papers or publications touching the visibility optimization in relation with tactical manoeuvre or other operational context are: Tsourdos and White (2010); Duan et al. (2007); Yao et al. (2005); Liu et al. (2004); Washburn \& Kress (2009); Mokrá (2012); Mazal et al. (2016); Rybansky (2014); Bruzzone (2018); Bruzzone and Massei (2017); Nohel (2019); Starý and Farlík (2020); Časar and Farlík (2020).

\section{Microrelief and its impact}

The problem is defined as a search of such an observation points (from the source are), from which we have a maximal observation coverage of the destination area and the number of these points is low as possible (minimum).

The best case, where we could find a oneobservation point from which we could see the whole destination area is usually very rare occasion.

So we need to apply other methods to find these points, if they are exists, what is actually a first test before the start of another process of solution, so if:

$$
\forall n \in N, \bigcup_{1}^{n} V_{n} \neq D ;
$$

$$
\begin{array}{ll}
D & \text { - point set of the destination area, } \\
V n & \text { - point set, } V_{n} \in D, \text { visible from } n, n \in N, \\
N & \text { - point set of the source area, } \\
n & - \text { Particular point from } N .
\end{array}
$$

there do not exists any set of potential observation points from the source area to observe complete destination area. In this case, there is just two options, select another source area (for instance scale it down to the set of k points, where $\forall k \in N, V_{k} \neq \emptyset$; ) or scale down the D:

$$
\forall n \in N, \quad D=\bigcup_{1}^{n} V_{n} ;
$$

The case could be used in the further approach and the problem is defined as:

$$
\bigcup_{1}^{n} V_{n}=\bigcup_{1}^{m} V_{m} ; n \in N, m \in M ; M \subset N, \min \rightarrow m
$$

Or, usually we could accept the case:

$$
\bigcup_{1}^{n} V_{n} \approx \bigcup_{1}^{m} V_{m} ; n \in N, m \in M ; M \subset N, \min \rightarrow m
$$

$$
\begin{array}{ll}
V_{m}- & \text { point set, } V_{m} \in D, \text { visible from } m, \\
& m \in N, \\
N- & \text { point set of the source area, } \\
M- & \text { point subset of the source area, } \\
n- & \text { particular point from } N, \\
m- & \text { particular point from } M .
\end{array}
$$

Especially, when the "approximate" solution (m) generate seriously lower numbers to "original one". In any case, further solution we attempt to calculate is [3], the [4] needs additional analyses and could be easily derived from the solution of [3]. Regarding the problem described by [3], as usually, there could exists more approaches. In any case, one of them, generating mathematically optimal solution is based on iterative search of all L combinations of the observations points on $\mathrm{N}$ and check if particular combination fulfills the solution [3], the brief algorithm description is follows:

1. $L=1$

2. Generate all L member combinations on $N$

3. Check if any $L$ member combination visibility to $D$ fulfills the [3]

4. If yes, the result is $L$, if not, $L=L+1$

5. If $L$ is out of $D$, there is the violation of the condition [2], algorithm fails

6. Continue by the step 2

The main application problem of described algorithm is very low efficiency, especially when $L>1$. Another approach, which generate mathematically pure optimal solution, was not found yet, on the other hand, there were developed an algorithm (by authors) which approximate the purely optimal solution to a significant reduction of the $\mathrm{M}$ comparing to the $\mathrm{N}$. The algorithm is based on iterative integration of the $V_{n}$ and elimination of all $M$ members, which creates a pure subset, brief algorithm description, is follows:

1. $L=1$

2. Generate the visibility set $V$ from $n=\operatorname{first}(N), n \in N$,

3. $n=\operatorname{next}(N), n \in N$,

4. Generate the visibility set $T$ from $n, n \in N$,

5. If $T \subset V$ continue by step 3 ,

6. If not $5, L=L+1, V=T \cup V$, continue by step 3

7. Return $L$

Described algorithm seriously decrease the count of necessary observation points, as demonstrated on the following pictures, were the observation "optimality map" (level of grey between white $-100 \%$ visibility to black - $0 \%$ visibility) was calculated and reduced set of observation positions identified (red circles), yellow lines indicates transitions between the positions within the reduced set:

where:

$$
V_{n}-\quad \text { point set, } V_{n} \in D \text {, visible from } n,
$$




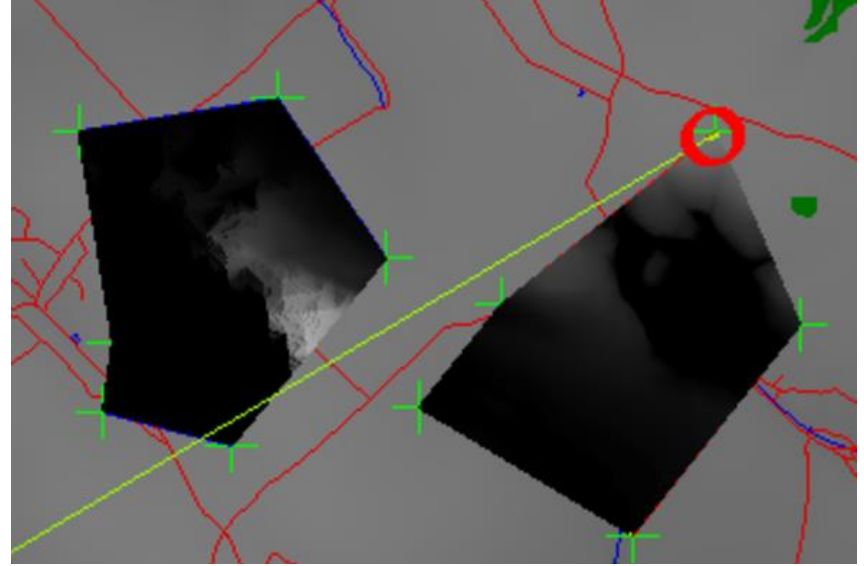

Figure 1: Example 1 - solution time: 35s, result: 5 locations creating the 1 isolated region, source area: $2.6 \mathrm{~km} 2$, destination area: $3.1 \mathrm{~km} 2$

The solution is highly dependent on the type of the space configuration of the terrain, it could vary from several neighborhood points to a hundreds distributed across the source area, where the approximation process according to the (4) has a sense to pass.

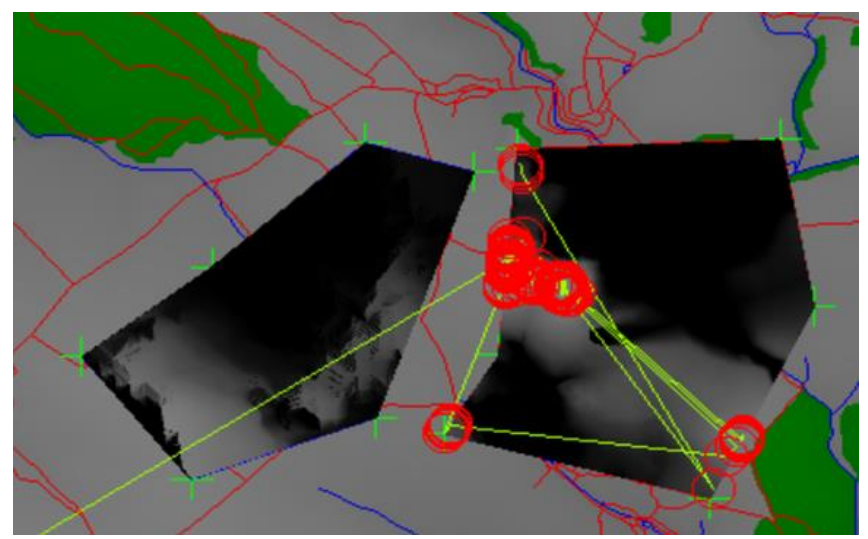

Figure 2: Example 2 - solution time: 155 s, result: 56 locations creating the 5 isolated regions, source area: $3.4 \mathrm{~km} 2$, destination area: $3 \mathrm{~km} 2$.

Explained approach was chosen to demonstrate a one of the possible way to the particular operational problem solution. It opens the opportunity of the operational automation of selected tasks and further exploitation in real time operational decision support in C4ISTAR systems.

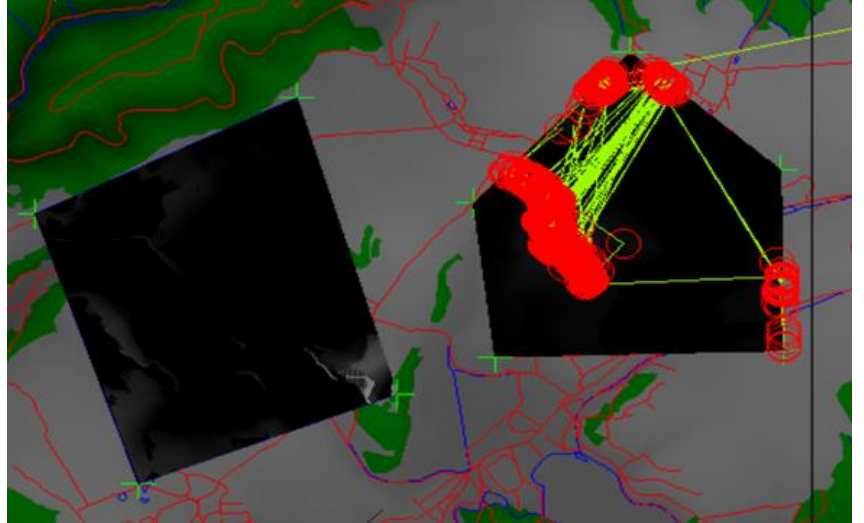

Figure 3: Example 3 - solution time: $334 \mathrm{~s}$, result: 182 locations creating the 5 isolated regions, source area: $2.7 \mathrm{~km} 2$, destination area: $3.4 \mathrm{~km} 2$.

The computer application was executed on PC with INTEL Core-7 $(2,4 \mathrm{GHz})$ processor and the solution takes approximately from 0.5 to 5.5 minutes, contemporary platform enables a parallel processing of selected tasks and it is going to be the field of further development.

\section{Conclusions}

The importance of effective search and displacement of observation components within almost any operation is very high. Especially in future operations, where we expect a higher orientation on real time ISR and stress on the task and asset distribution effectiveness. The mentioned problem was usually solved in practice intuitively and experimentally with or without some computer support. Computer generated solution shows, that it is sufficient to visit just a small portion of the source area to fulfil the ground observation task and save the time, asset and effort in any operation. The presented solution could be further optimized and enriched by additional features and attributes linked to tactical aspects of the operational area. This will be the field of further research and development.

\section{References}

Bruzzone, A.G. \& Massei, M. (2017). "Simulation-Based Military Training", in Guide to Simulation-Based Disciplines, Springer, pp. 315-361.

Bruzzone, A.G. (2018). "MS2G as Pillar for Developing Strategic Engineering as a New Discipline for Complex Problem Solving", Keynote Speech at I3M, Budapest, September

ČASAR, Josef, FARLÍK, Jan. The Possibilities and Usage of Missile Path Mathematical Modelling for the Utilization in Future Autonomous Air Defense Systems Simulators. In: Jan Mazal, Adriano Fagiolini, Petr Vasik. Modelling and Simulation for Autonomous Systems. Cham, Switzerland: Springer Nature, 2020, roč. 2019, č. LNCS 11995, p. 253-261. ISSN 0302-9743. ISBN 978-3-030-43890-6. 
Duan, H. B., Ma, G. J., Wang, D. B., Yu, X. F. (2007). An improved ant colony algorithm for solving continuous space optimization problems. Journal of System Simulation, 19(5): 974-977.

Liu, C.A., Li, W.J, Wang, H.P. (2004). Path planning for UAVs based on ant colony, Journal of the Air Force Engineering University, 2(5):9-12.

Mazal, J., Stodola, P., Procházka, D., Kutěj, L., Ščurek, R., Procházka, J. (2016). Modelling of the UAV safety manoeuvre for the air insertion operations. In: Modelling and Simulation for Autonomous Systems, MESAS 2016. Rome: Springer International Publishing, p. 337-346. ISSN 03029743. ISBN 978-3-319-47604-9.

Mokrá, I. (2012) Modelový přístup k rozhodovacím aktivitám velitelů jednotek $\mathrm{v}$ bojvých operacích. Disertační práce. Brno: Univerzita obrany v Brně, Fakulta ekonomiky a managementu. $120 \mathrm{~s}$.

NOHEL, Jan. Possibilities of Raster Mathematical Algorithmic Models Utilization as an Information Support of Military Decision Making Process. In: Modelling and Simulation for Autonomous Systems. Cham, Switzerland: Springer: NATO Modelling and Simulation Centre, 2019, p. 553-565. ISSN 03029743. ISBN 978-3-030-14984-0. DOI: 10.1007/978-3-030-14984-0_41.

Rybansky, M. (2014). Modelling of the optimal vehicle route in terrain in emergency situations using GIS data. In: 8th International Symposium of the Digital Earth (ISDE8) 2013, Kuching, Sarawak, Malaysia 2014 IOP Conf. Series.: Earth Environmental Science 18 012071, doi:10.1088/1755-1315/18/1/012131, http://dx.doi:10.1088/1755-1315/18/1/012131. ISSN 1755-1307.

STARÝ, Vadim, FARLÍK, Jan. Aspects of Air Defence Units C2 System Modelling and Simulation. In: Jan Mazal, Adriano Fagiolini, Petr Vasik. Modelling and Simulation for Autonomous Systems. Cham, Switzerland: Springer Nature, 2020, roč. Neuveden, p. 351-360. ISSN 0302-9743. ISBN 978-3-03043890-6.

Tsourdos, A., White, B., Shanmugavel, M. (2010). Cooperative Path Planning of Unmanned Aerial Vehicles, ISBN: 978-0-470-74129-0, 214 pages, WILEY, November.

Washburn, A. \& Kress, M. (2009) Combat Modeling. International Series in Operations Research \& Management Science. Springer.

Yao, H.Q., Quan P., Jian, G.Y. (2005). Flight path planning of UAV based on heuristically search and genetic algorithms, Proceedings of the IEEE 32nd Annual Conference,45-50. 